\title{
Intraosseous Ganglion of the Ankle: A Case Report
}

\author{
by Vasu Pai MS, D (Orth), National board (Orth), FICMR, FRACS, MCh (Orth) ${ }^{1}$, \\ Vishal Pai, M.B., Chb 2
}

The Foot \& Ankle Journal 1 (3): 2

The case of a 52 year-old man with a persistent ganglion cyst of the dorsolateral aspect of the ankle is presented. At excision, the ganglion communicated to a cystic region within the bone of the lateral malleolus. The patient was treated with curettage of the lateral malleolus and cancellous bone grafting.

Key words: Intraosseous ganglion, lateral malleous, ganglion, benign tumor

Accepted: February 10, 2008

Published: March 1, 2008

This is an Open Access article distributed under the terms of the Creative Commons Attribution License. It permits unrestricted use, distribution, and reproduction in any medium, provided the original work is properly cited. @The Foot \& Ankle Journal (www.faoj.org)

Ganglia are most commonly located around the wrist as a soft tissue swelling with a pedicle. This can be traced to the scapholunate or radioscaphoid joints or surrounding tendon sheath. Intraosseous ganglion are rarely reported and occur mainly as carpal bone cysts. ${ }^{1,2,3,4}$

A ganglion cyst of the lateral malleolus is a rare occurrence with only one report in the literature. ${ }^{5}$ We report a case of an intraosseous ganglion of the lateral malleolus with soft tissue swelling. There was communication between an intraosseous ganglion and the overlying the soft tissue cyst.

\footnotetext{
Address correspondence to: Dr. Vasu Pai, Gisborne Hospital, Ormand Road, Gizborne, New Zealand.

E-mail: vasuchitra@gmail.com

${ }^{1}$ Orthopaedic Specialist, Gisborne, Hospital, Ormand Road, Gisborne, New Zealand.

2 House Surgeon, Middlemore Hospital, Auckland, New Zealand.
}

\section{Case Report}

A 52 year-old man was referred for treatment of swelling involving the lateral aspect of his right ankle. Two years before presentation, the swelling appeared to have grown to significant size with associated aching pain. The patient also noticed pain around his ankle on weight bearing.

Upon further inquiry, the patient reports a twisting injury to his right ankle in a rugby game that occurred in 1972. The injury was treated by cast immobilization and physiotherapy. The patient then underwent surgical repair in 1975 of which the details were not available. This surgery was successful and he was able to go back to work and also play rugby.

Physical examination revealed a $6 \mathrm{~cm}$ diameter swelling over the dorsolateral aspect of the right ankle. There was no warmth or tenderness over the swelling. Swelling appeared fixed to the lateral malleolus. There was deep tenderness over the posterior aspect of lateral malleolus. (Fig 1) 


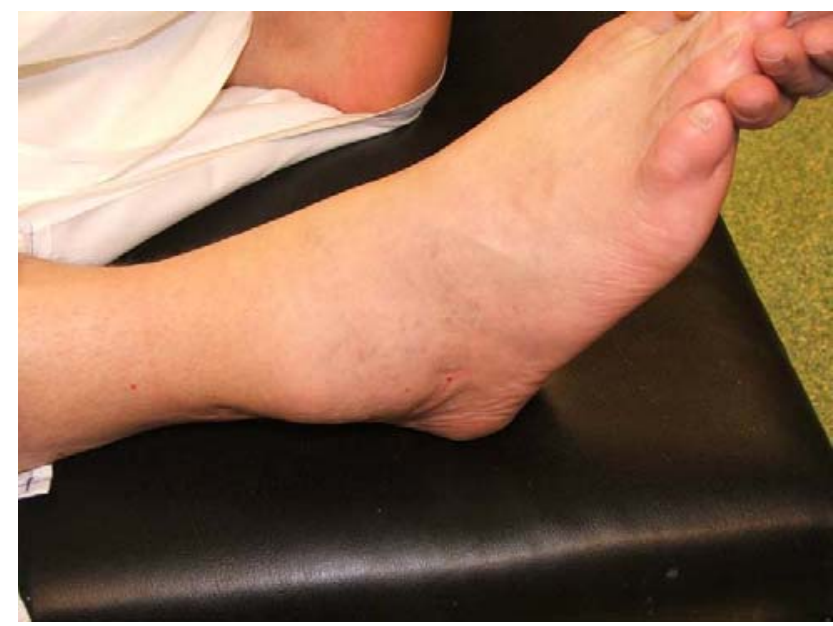

Figure 1 Soft tissue swelling of the right lateral ankle.

Examination of the ankle revealed a range of motion of $15^{\circ}$ dorsiflexion and $30^{\circ}$ plantar flexion of the ankle, motion beyond which was painful. There was evidence of joint effusion and tenderness over the joint line on deep palpation. Distal neurovascular status appeared normal.

Blood examination including total lymphocyte count, ESR, CRP, rheumatoid factor and serum uric acid were unremarkable.

Magnetic resonance imaging of the foot showed discrete fluid collections both outside as well as within the lateral malleolus and was consistent with diagnosis of benign swelling of ganglion. (Fig . 2)

Plain radiograph revealed moderate osteoarthritis of the ankle with joint space narrowing. There was a subtle multiloculated osteolytic lesion in the lateral malleolus with thin sclerotic margins along the intramedullary portion of the lateral malleolus. The distal fibula had mild remodeled expansion with thin cortical bone. There was a huge soft tissue swelling related to the lateral malleolus. (Fig. 3ab)

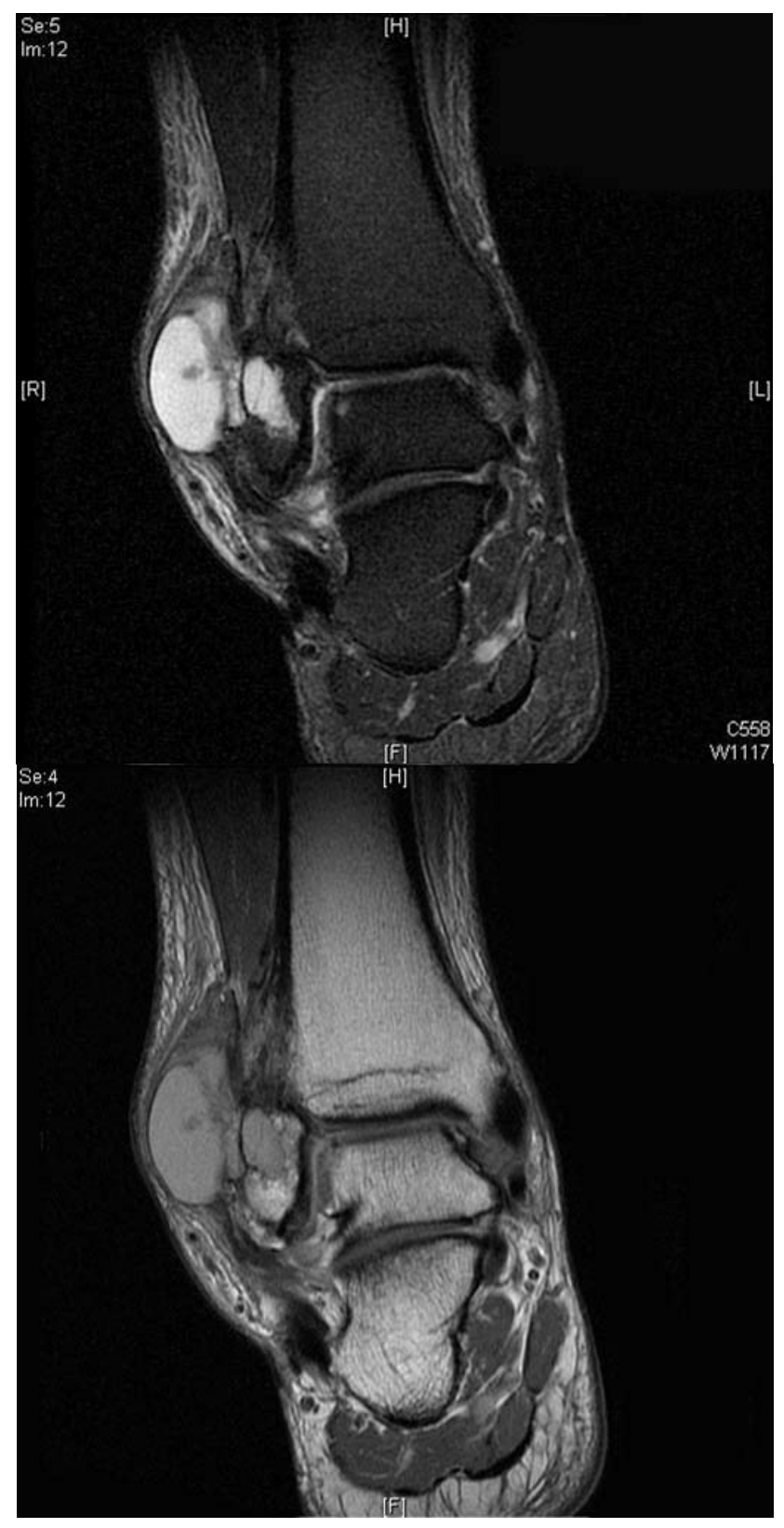

Figure 2 Coronal T2 and T1 weighted MR image showing a well defined homogeneous bright signal in $\mathrm{T} 2$ and decrease signal in T1, extending into the Anterolateral soft tissues. 


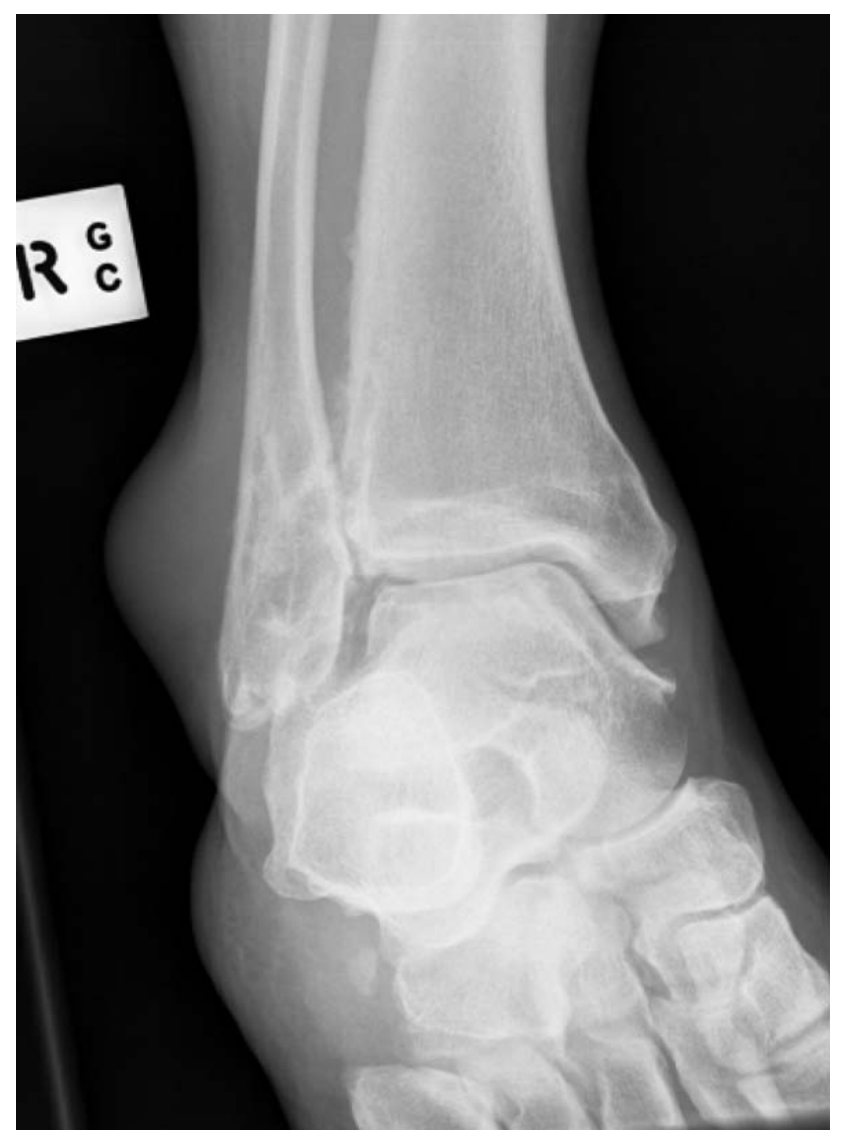

Figure 3a Ankle mortise view showing soft tissue swelling lateral to lateral malleolus. A multiloculated osteolytic lesion is seen in the distal fibula.

The differential diagnosis includes giant cell tumor, gouty arthropathy, ganglion cyst, aneurysmal bone cyst or synovial sarcoma.

Under tourniquet control the ganglion was excised through a lateral incision. There was a 4 $\mathrm{cm} \times 4 \mathrm{~cm}$ soft cystic mass which communicated directly with the lateral malleolus. There was a small defect over the posterior aspect of the malleolus. (Fig. 4)

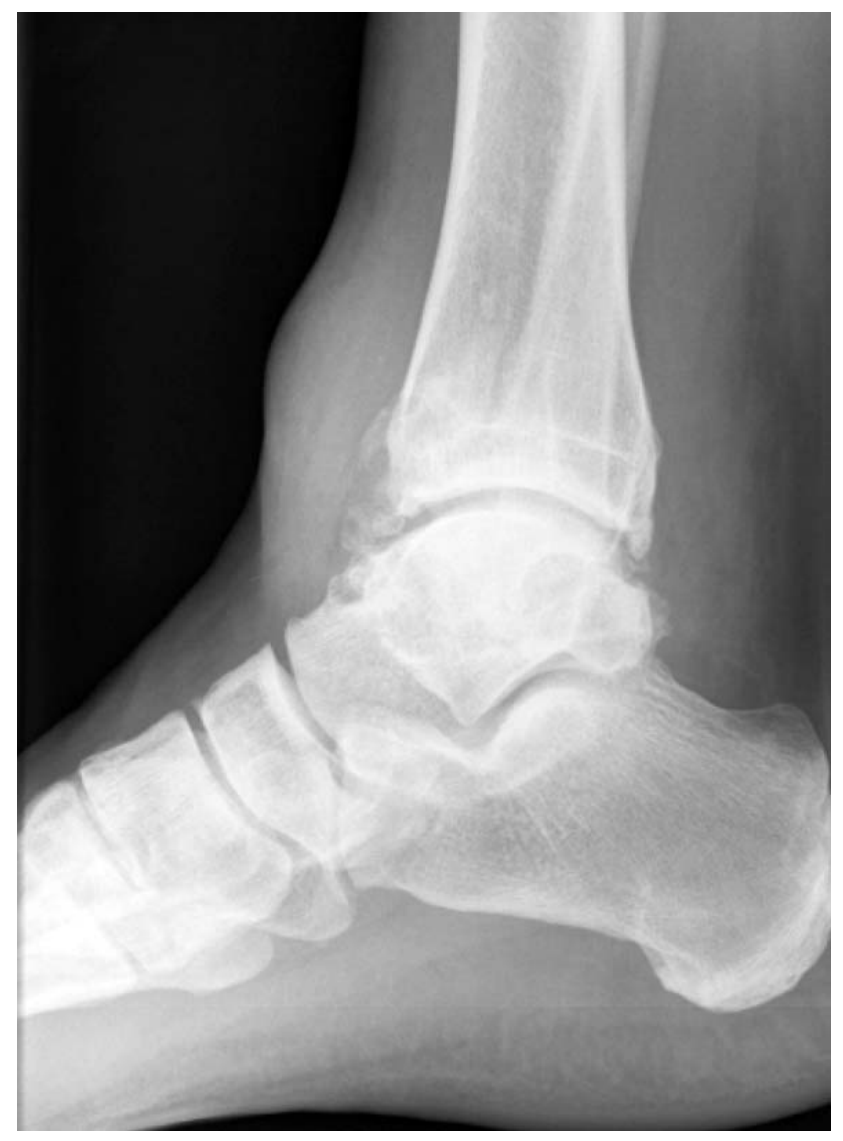

Figure $\mathbf{3 b}$ Lateral radiograph showing diffuse osteoarthritis of the anterior and posterior ankle mortise. Soft tissue swelling is also appreciated anteriorly.

Histology was consistent with a diagnosis of intraosseous ganglion of the lateral malleolus with extra-osseous extension. The fibrous wall of the cyst showed no definite synovial lining and the mucoid content of the cyst was represented by indefinite stands.

There was evidence of mucoid degeneration within the fibrous wall.

With the resumption of normal activities, the reconstruction remains intact without evidence of recurrence of the ganglion in the 2.5 years after surgery. 


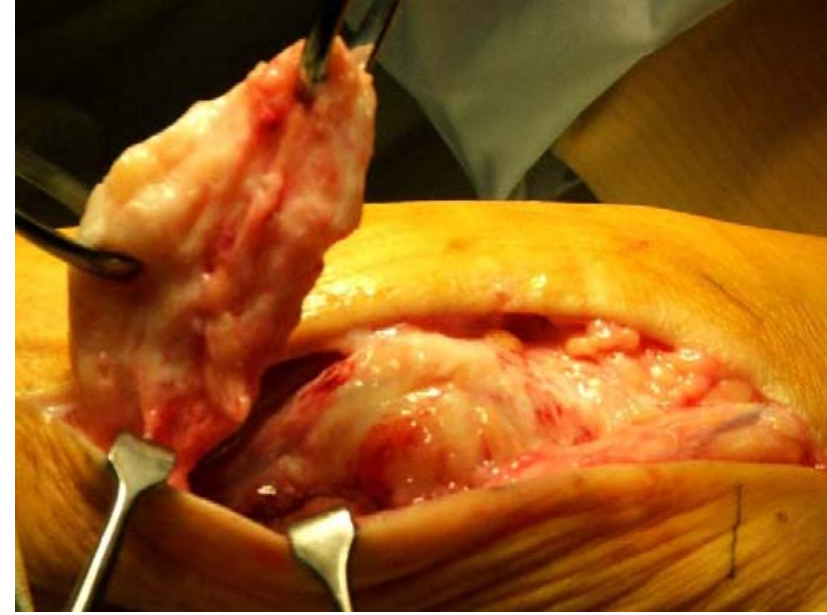

Figure 4 Intra-operative photograph showing dissected superficial swelling from the lateral malleolus.

\section{Discussion}

Ganglion cysts are common mucin-containing tumors that affect a wide variety of joints of the body, including those of the foot and ankle. Despite their benign histology, the cysts can be problematic.

Pain and mass effects associated with the lesions can make ambulation and wearing shoes difficult.

In 1989, a series of 83 cases of soft-tissue tumor of the foot and ankle were retrospectively analyzed to determine the relative frequency of the lesions. ${ }^{15}$ Seventy-two (87 percent) of the tumors were benign. Ganglion cysts and plantar fibromatoses were the most common. Ganglion have also been described in rarer areas of tendon, nerve and bone $6,7,8$

The etiology of intraosseous ganglia is uncertain. It has been shown by Landels that cysts in osteoarthritis arose from an intrusion of synovial fluid into bone at the joint surface. ${ }^{9}$
Kambolis reviewed 15 cases of ganglionic cystic defects of bone, and suggested that the intraosseous lesion was the result of extension of the overlying soft tissue ganglion into bone. ${ }^{8}$ Other theories as to the cause of intraosseous ganglia include degeneration in intramedullary connective tissue and metaplasia of skeletal connective tissue

In a review of 54 cases of ganglion cyst, Rozbruch reported 4 patients with intraosseous ganglia located in the proximal tibia, patella and the first metatarsal head. ${ }^{10}$ They also suggested that curettage of the bone gives better results. Isolated tarsal ganglion without soft tissue has also been reported. ${ }^{11,12,13,14}$ A ganglion cyst of the lateral malleolus with a soft tissue extension is a rare occurrence, and there was only one report found in a literature review. ${ }^{5}$

Surgical excision is required in the majority of cases to confirm the diagnosis as well as alleviate pain when conservative measures are unsuccessful. The recurrence rate following excision of soft tissue ganglions can range from of 7 to 43 percent. ${ }^{15}$ It appears that the recurrence following curettage of an intraosseous ganglion is rare. ${ }^{16}$

Bone lesions with a similar radiographic appearance (giant cell tumors, aneurysmal bone cyst, enchondromas, synovial sarcoma and gouty arthropathy) must be differentiated from intraosseous ganglia. Curettage of the cyst followed by packing of the defect with bone graft is the treatment of choice. 


\section{References}

1. Tuzuner T, Subasi M, Alper M, Kara H, Orhan Z. : Penetrating type intraosseous ganglion cyst of the lunate bone West Indian Med J. 54(6):384-6, 2005.

2. De Smet L, Van Ransbeeck H.Intraosseous ganglion of the triquetrum. A transpisiformal approach. : Acta Orthop Belg. 66(2):194-6, 2000.

3. Fealy MJ, Lineaweaver W.Intraosseous ganglion cyst of the scaphoid.: Ann Plast Surg. 34(2):215-7, 1995.

4. Ikeda M, Oka Y.: Cystic lesion in carpal bone. Hand Surg. ;5(1):25-32, 2000.

5. Ahn JI, Park JS. Intraosseous ganglion. Report of a case.Int Orthop.;17(3):184-7, 1993.

6. Costa CR, Morrison WB, Carrino JA, Raiken SM. MRI of an intratendinous ganglion cyst of the peroneus brevis tendon. : Clin Orthop Relat Res.;445:254-60, 2006.

7. Adn M, Hamlat A, Morandi X, Guegan Y. Intraneural ganglion cyst of the tibial nerve. Acta Neurochir (Wien). 148(8):885-9; 2006.

8. Kambolis C, Bullough PG, Jaffe HI. Ganglionic cystic defects of bone. L Bone Joint Surg Am. 55(3):496-505, 1973. 9. Landells JW. The bone cysts of osteoarthritis. J Bone Joint Surg 35B,643-6,1953.

10. Rozbruch SR, Chang V, Bohne WH, Deland JT. Ganglion cysts of the lower extremity. Orhopedics 21:141148, 1998.

11. Murff R, Ashry HR. Intraosseous ganglia of the foot. I Foot Ankle Surg.;33(4):396-401,1994.

12. Uysal M, Akpinar S, Ozalay M. Arthroscopic debridement and grafting of intraosseous talar ganglion. Arthroscopy.21(10);1269,2005.

13. Wu KK. Intraosseous ganglion cyst of the middle cuneiform bone of the foot. J foot ankle surg 33(6):633-5, 1994.

14.Seymour $\mathrm{N}$ Intraosseous ganglia of medial malleolus, JBJS[Br] (50),134-7,1968.

15. Kirby EI, Shereff MI, Lewis MM.Soft-tissue tumors and tumor-like lesions of the foot. An analysis of eighty-three cases. JBJS (Am). Apr;71(4):621-6, 1989.

16. Pontius J, Good J, Maxian S. Ganglions of the foot and ankle, an retrospective analysis of 63 procedures. J Am Pod Assoc 89:163 168, 1999. 